Brazilian Journal

of Chemical

Engineering

\title{
OPTIMIZATION OF LIPASE IMMOBILIZATION ON MAGHEMITE AND ITS PHYSICO-CHEMICAL PROPERTIES
}

\author{
Maryam F. K. Ariffin ${ }^{1}$, Ani Idris ${ }^{1 *}$ and Nor H. A. Ngadiman ${ }^{2}$ \\ ${ }^{1}$ Universiti Teknologi Malaysia, Faculty of Chemical and Energy Engineering, Institute of Bioproduct Development, Johor, Malaysia. \\ ORCID: 0000-0002-9191-3811; E-mail: ani@cheme.utm.my, ORCID: 0000-0002-2008-4913 \\ ${ }^{2}$ Universiti Teknologi Malaysia, Faculty of Mechanical Engineering, Department of Materials, Manufacturing and Industrial Engineering, \\ Johor, Malaysia. ORCID: 0000-0002-1128-6556
}

(Submitted: April, 26, 2018 ; Revised: August 29, 2018 ; Accepted: September 3, 2018)

\begin{abstract}
Nanomaterial-based biocatalysts have emerged as current carriers suitable for enzyme immobilization. The nano-sized materials provide large surface area for enzyme attachment, thus increasing the probability for its efficient catalyst activity. By using magnetized nanomaterials, enhancement of the downstream processing is evident as it eases the immobilized enzyme separation from the reaction mixture further. Lipase / maghemite composites were prepared by initial maghemite surface modification to cater to the needs for biocatalyst attachment. Surface modification using chitosan and subsequent cross-linking with glutaraldehyde provide a suitable environment for the enzyme to be immobilized. Optimization of the conditions for lipase immobilization was carried out using a response surface methodology (RSM) experimental design to obtain the precise optimized conditions for the process. Selected process variables involved were chosen and optimized conditions for lipase immobilization were 9 hour incubation time, $55^{\circ} \mathrm{C}$ incubation temperature and $12 \%(\mathrm{v} / \mathrm{v})$ glutaraldehyde content. The optimized immobilized lipase activity was $1.8 \mathrm{U}$. Characterizations of the on synthesized materials were also performed. The size distribution of maghemite nanomaterials was mainly within the range of 2-3 nm. Thermal properties of the synthesized maghemite was investigated using DSC and TGA analyses and we found that maghemite changes to hematite at $456.3^{\circ} \mathrm{C}$. Magnetic properties of both untreated and lipase immobilized maghemite were studied using VSM and both were superparamagnetic nanomaterials with saturation magnetizations of 34.3 and 80.3 , respectively.

Keywords: Maghemite; Response surface methodology; Optimization; Lipase immobilization.
\end{abstract}

\section{INTRODUCTION}

A nano-scale size maghemite and its biocompatibility enhance its desirability to be used as an enzyme immobilization matrix. This allows green technology to be manipulated in a wide range of applications. Having a very small particle size, maghemite provides large surface area for protein attachment and shorter substrate diffusional path (Ghadi et al., 2015; Kim et al., 2005). Apart from that, the magnetic property of maghemite eases the downstream processing as the immobilized enzyme can be easily separated by applying an external magnetic field. Surface modification of the target maghemite is needed to further increase the efficiency during enzyme immobilization. For instance, chitosan (2-amino-2-deoxy-( $1 \rightarrow 4)-\beta$-D-glucan); a type of polysaccharide with amino functional groups is suitable for protein conjugation through cross linking agent such as glutaraldehyde (Kuo et al., 2012). The support containing chitosan can retain more than $80 \%$ of immobilized enzyme activity after a number

\footnotetext{
* Corresponding author: Ani Idris - E-mail: ani@cheme.utm.my
} 
of hydrolytic cycles (Chiou \& Wu, 2004; Romdhane, Romdhane, Gargouri, \& Belghith, 2011). Furthermore, a maghemite coated chitosan was light, exhibited enhanced tensile strength, high flexibility with tunable magnetic and electrical properties (Saravanan \& Ramasamy, 2016).

Lipase (EC 3.1.1.3) is an enzyme that belongs to the hydrolase family that natively hydrolyzes triacylglycerides to simpler products of glycerol and fatty acids at the water-oil interface. The system, however, changes when lipase is used in organic solutions, where it can catalyze formation of ester bonds in the presence of a minimal amount of water for enzyme activation. By immobilizing it onto a suitable carrier, the function of lipase can be tailored for specific required reactions of interest with enhanced stability at high enzyme activity. Compared to the free enzyme, the immobilized lipase shows advantages over the former through higher catalytic stability, functionality over continuous operations and lower operating cost, especially in the downstream processing (Liu et al., 2012).

Previously, there were many studies reporting on lipase immobilization using silica grafted ferrofluids (Cipolatti et al., 2014; Shaarani et al., 2016). In this study, we used chitosan as the maghemite coating agent with sodium tripolyphosphate to assist crosslinking with glutaraldehyde before being treated with lipase enzyme. By applying such a composite, an enhance probability for efficient lipase immobilization can occur due to increase in the number of amine sites for enzyme attachment. To the best of our knowledge, such a composite has yet to be explored widely. The covalent lipase immobilization process was done using a response surface methodology (RSM) statistical analysis to find the optimum conditions. The method allows the determination of the optimum region with evaluation of the significance of dependent and independent variables with reduced numbers of experiments (Kuo et al., 2012). Physicochemical properties of both modified maghemite and immobilized lipase were also studied in order to understand the system better.

\section{METHODOLOGY}

\section{Synthesis of maghemite nanoparticles}

Chemical composition and route of synthesis of maghemite followed (Idris, Ismail, Hassan, Misran, \& Ngomsik, 2012). Briefly, $\mathrm{FeCl}_{2}$ and $\mathrm{FeCl}_{3}$ (mol ratio $1: 3$ ) were added to $2 \mathrm{M} \mathrm{HCl}$ followed by addition of 2.2 $\mathrm{M} \mathrm{NH}_{3(\mathrm{aq})}$. The mixture was then stirred for 30 minutes before removing the upper phase by treating it with an external magnet. The remaining solution was washed with deionized water and subjected to upper phase removal by using an external magnet again. To convert the solution to maghemite, $\mathrm{HNO}_{3}$ and $\mathrm{Fe}\left(\mathrm{NO}_{3}\right)_{3}$ at $1: 1(\mathrm{v} / \mathrm{v})$ were added and solution was mixed and boiled for 30 minutes. The unreacted reagent was then removed by magnetic removal. The mixture was then washed with acetone and diethyl ether alternately before being dried overnight to recover the solid phase of maghemite.

\section{Surface modification of synthesized maghemite nanoparticles}

Initially, $1 \%(\mathrm{w} / \mathrm{w})$ chitosan was prepared by dissolving it in $1.5 \%(\mathrm{v} / \mathrm{v})$ acetic acid of $\mathrm{pH} 4.0$. Then, $0.1 \mathrm{~g}$ of maghemite was added into $20 \mathrm{ml}$ of prepared chitosan and mixed via sonication to ensure even coating. The excess chitosan was removed by washing the solution with deionized water and separated with an external magnet. The complex was then dispersed into $0.5 \mathrm{mg} / \mathrm{ml}$ sodium tripolyphosphate (TPP) to form a maghemite/chitosan/TPP composite.

\section{Response surface methodology (Box-Behnken) experimental design for lipase immobilization}

A total number of 30 runs was generated by using Box- Behnken design in RSM of Minitab ${ }^{\circledR}$ software and performed in two replicates. The design is an independent quadratic design that does not involve preliminary full factorial design. This provides advantages over experimental runs with few factors since no screening experiment was conducted since to only 3 factors were involved. Lipase from Candida antarctica supplied from Sigma-Aldrich was used throughout without further purification. The summary of immobilization parameters is shown in Table 1.

The response to the immobilization efficiency was calculated using the immobilized lipase activity (U) post treatment. The hydrolysis of $p$-nitrophenyl palmitate was performed in a homogenized phosphate buffer ( $\mathrm{pH}$ 7) with acacia gum and Triton $\mathrm{X}-100$ as emulsifiers at $37^{\circ} \mathrm{C}$. Immobilized lipase activity was then measured using a UV-Vis spectrophotometer at $410 \mathrm{~nm}$. One unit of enzyme activity is defined as the amount of enzyme required to liberate $1 \mu \mathrm{mol}$ of $p$-nitrophenol per minute. Activity of the immobilized lipase was calculated using Equation (1):

Table 1. Summary for Lipase Immobilization on Surface Modified Maghemite.

\begin{tabular}{cccc}
\hline & \multicolumn{3}{c}{$\begin{array}{c}\text { Coded form of parameters } \\
\text { tested with corresponding values }\end{array}$} \\
\cline { 2 - 4 } Level & $\mathbf{X}_{\mathbf{1}}$ & $\mathbf{X}_{\mathbf{2}}$ & $\mathbf{X}_{\mathbf{3}}$ \\
\cline { 2 - 4 } & $\begin{array}{c}\text { Incubation } \\
\text { temperature } \\
\left({ }^{\mathbf{C}} \mathbf{C}\right)\end{array}$ & $\begin{array}{c}\text { Incubation } \\
\text { time } \\
(\mathbf{h r})\end{array}$ & $\begin{array}{c}\text { Glutaraldehyde } \\
\text { content } \\
(\mathbf{\%})\end{array}$ \\
\hline-1 & 25 & 3 & 4 \\
0 & 40 & 6 & 8 \\
1 & 55 & 9 & 12 \\
\hline
\end{tabular}


$\operatorname{Immobilized~lipase~activity~}(\mathrm{U})=\frac{\Delta \mathrm{OD}_{410} \times \mathrm{V}_{\mathrm{S}}}{\mathrm{V}_{\mathrm{ls}} \times \varepsilon_{410}}$

where $\Delta \mathrm{OD}_{410}=$ gradient value for production of p-nitrophenol at $410 \mathrm{~nm}$; Vs $=$ volume of total sample $(\mathrm{mL}) ; \mathrm{V}_{\mathrm{ls}}=$ volume of reaction mixture $(\mathrm{mL}) ; \varepsilon_{410}=$ value for the p-nitrophenol molar extinction coefficient measured at $410 \mathrm{~nm}$, which is $61865.6 \mathrm{~L} \mathrm{~mol}^{-1} \mathrm{~cm}^{-1}$

\section{Physico-Chemical Characterization of Synthesized Maghemite and Lipase / Maghemite Composite}

Confirmation of maghemite nanoparticles was done using X-Ray powder diffraction (XRD) on a Siemens XRD Diffractometer D5000 using $\mathrm{Cu}-\mathrm{K} \alpha$ radiation. FT-IR spectra were obtained using an ATR - FTIR (Shimadzu, IRTracer - 100). The morphology of the synthesized maghemite nanoparticles was confirmed using High Resolution Transmission Electron Microscopy (HRTEM) at $200 \mathrm{kV}$. Thermal properties of synthesized maghemite were investigated through differential scanning calorimetry (DSC) under a nitrogen flow rate of $50 \mathrm{ml} \mathrm{min}{ }^{-1}$. The range of temperature applied during analysis was from ambient temperature to $500^{\circ} \mathrm{C}$ with a temperature ramp of $10{ }^{\circ} \mathrm{C} \mathrm{min}^{-1}$. Analysis of maghemite weight loss with increase in temperature was performed through thermogravimetric analysis (TGA) using the temperature range from ambient temperature to 650 ${ }^{\circ} \mathrm{C}$ under continuous nitrogen flow with a temperature ramp of $10^{\circ} \mathrm{C} \mathrm{min}^{-1}$. Degrees of iron oxide nanoparticle magnetization were visualized quantitatively using Vibrating Sample Magnetometer (VSM) model Lakeshore 7404 series in a magnetic field up to $\pm 15 \mathrm{G}$ at room temperature

\section{RESULTS AND DISCUSSION}

\section{Box-Behnken Design of lipase immobilization on surface-modified maghemite}

Box-Behnken analysis was measured using the enzyme activity of immobilized lipase enzyme on maghemite. The experiments were performed using Box-Behnken response surface design randomly in two replicates to find the optimized region. Responses generated from the experimental runs are tabulated in Table 2. Significance of each parameter tested was calculated using ANOVA at $\alpha=0.05$ and mathematical correlations using least square method conducted by fitting the amount of product formed at desired parameters in Table 2.

Dependency on the model towards the system was measured through model fitting analyses (Table $3)$. Values of $R^{2}$ and lack-of-fit will determine the accuracy of the model. High value of $\mathrm{R}^{2}$ shows that the model fits the experimental data very well. The non-
Table 2. Parameters studied for optimization of lipase immobilization on maghemite using Box-Behnken design.

\begin{tabular}{|c|c|c|c|c|c|}
\hline No & $\begin{array}{c}\text { Run } \\
\text { Order }\end{array}$ & $\begin{array}{c}\mathbf{X}_{1} \\
\left({ }^{\circ} \mathrm{C}\right)\end{array}$ & $\begin{array}{c}\mathrm{X}_{2} \\
\text { (hr) }\end{array}$ & $\begin{array}{c}\mathbf{X}_{3} \\
(\%)\end{array}$ & $\begin{array}{l}\text { Lipase } \\
\text { activity } \\
\text { (U) }\end{array}$ \\
\hline 1 & 4 & 55 & 9 & 8 & 1.26 \\
\hline 2 & 15 & 40 & 6 & 8 & 0.51 \\
\hline 3 & 3 & 55 & 3 & 8 & 0.24 \\
\hline 4 & 8 & 40 & 9 & 12 & 1.00 \\
\hline 5 & 14 & 40 & 6 & 8 & 0.47 \\
\hline 6 & 7 & 40 & 3 & 12 & 0.42 \\
\hline 7 & 12 & 55 & 6 & 12 & 1.28 \\
\hline 8 & 10 & 55 & 6 & 4 & 0.46 \\
\hline 9 & 11 & 25 & 6 & 12 & 0.72 \\
\hline 10 & 1 & 25 & 3 & 8 & 1.00 \\
\hline 11 & 2 & 25 & 9 & 8 & 0.45 \\
\hline 12 & 5 & 40 & 3 & 4 & 0.47 \\
\hline 13 & 9 & 25 & 6 & 4 & 0.52 \\
\hline 14 & 6 & 40 & 9 & 4 & 0.64 \\
\hline 15 & 13 & 40 & 6 & 8 & 0.50 \\
\hline 16 & 22 & 40 & 3 & 12 & 0.42 \\
\hline 17 & 23 & 40 & 9 & 12 & 0.90 \\
\hline 18 & 20 & 40 & 3 & 4 & 0.44 \\
\hline 19 & 25 & 55 & 6 & 4 & 0.46 \\
\hline 20 & 17 & 25 & 9 & 8 & 0.48 \\
\hline 21 & 21 & 40 & 9 & 4 & 0.58 \\
\hline 22 & 29 & 40 & 6 & 8 & 0.70 \\
\hline 23 & 19 & 55 & 9 & 8 & 1.34 \\
\hline 24 & 18 & 55 & 3 & 8 & 0.23 \\
\hline 25 & 27 & 55 & 6 & 12 & 1.30 \\
\hline 26 & 16 & 25 & 3 & 8 & 0.90 \\
\hline 27 & 28 & 40 & 6 & 8 & 0.70 \\
\hline 28 & 26 & 25 & 6 & 12 & 0.72 \\
\hline 29 & 30 & 40 & 6 & 8 & 0.57 \\
\hline 30 & 24 & 25 & 6 & 4 & 0.49 \\
\hline
\end{tabular}

Table 3. Model fitting test results.

\begin{tabular}{cc}
\hline Model parameter & Value \\
\hline $\mathrm{R}^{2}$ & $91.3 \%$ \\
Adjusted $\mathrm{R}^{2}$ & $86.7 \%$ \\
Predicted $\mathrm{R}^{2}$ & $77.1 \%$ \\
p-value for lack of fit & 0.062 \\
\hline
\end{tabular}

significant value of lack-of-fit $(\mathrm{p}>0.05)$ shows that the model is in good agreement with the experimental data.

ANOVA ( $\alpha=0.05)$ test was conducted to evaluate the effect of parameters applied to the system (Table 4). In the analysis, the $T$ value is used to determine the significance of the regression coefficients of parameters and the $p$-value is the smallest level of significance for rejecting the null hypothesis (Jaiswal, Prakash, Talat, Hasan, \& Pandey, 2012).

From the ANOVA test conducted, all the linear parameters tested were found to be significant towards efficiency of lipase immobilization on maghemite with $p$ values less than 0.05 . High $T$-value of both incubation time and glutaraldehyde content show that both of these linear parameters have greater effect toward activity of immobilized lipase compared with 
Table 4. ANOVA of parameters tested.

\begin{tabular}{lcc}
\hline \multicolumn{1}{c}{ Parameter } & $\begin{array}{c}\text { T- } \\
\text { value }\end{array}$ & $\begin{array}{c}\text { P- } \\
\text { Value }\end{array}$ \\
\hline Incubation Temperature $\left({ }^{\circ} \mathrm{C}\right)$ & 2.83 & 0.011 \\
Incubation Time $(\mathrm{hr})$ & 5.55 & 0.000 \\
Glutaraldehyde $(\%)$ & 5.92 & 0.000 \\
Incubation Time * Incubation Time & 0.33 & 0.770 \\
Incubation Temperature * Incubation & 3.55 & 0.002 \\
Temperature & 0.48 & 0.639 \\
\% Glutaraldehyde *\% Glutaraldehyde & 9.62 & 0.000 \\
Incubation Time * Incubation & 2.33 & 0.031 \\
Temperature & 3.82 & 0.001 \\
Incubation Time * \% Glutaraldehyde & & \\
Incubation Temperature *\% & \\
Glutaraldehyde & &
\end{tabular}

incubation temperature. The results also indicate that the immobilized enzyme activity has a linear and positive relationship with all of linear parameters tested.

For the quadratic interactions between the parameters and immobilized lipase activity, the results from Table 4 shows that incubation time*incubation temperature has the strongest quadratic effect with highest $T$ - value compared with other interaction effects. From the generated data, regression analysis for Box-Behnken was calculated and the full quadratic model (uncoded) is shown in Equation (2):

$$
\begin{aligned}
\text { Lipase activity }(\%) & =4.161-0.3726 \mathrm{~A}-0.1197 \mathrm{~B}-0.1272 \mathrm{C}+ \\
& +0.00153 \mathrm{~A}^{2}+0.000661 \mathrm{~B}^{2}+0.00125 \mathrm{C}^{2}+ \\
& +0.008611 \mathrm{AB}+0.00781 \mathrm{AC}+0.002562 \mathrm{BC}
\end{aligned}
$$

where: $\mathrm{A}=$ Incubation Time; $\mathrm{B}=$ Incubation Temperature, $\mathrm{C}=$ Percentage of Glutaraldehyde.
Based on the main effect plots (Figure 1), the activity of immobilized lipase was found highest at all of the upper points of each parameter tested. Almost equal effects on the immobilized lipase activity are observed for both incubation time and glutaraldehyde content $(\sim 85 \%)$ when both are at their highest point. Both of the parameters (incubation time and glutaraldehyde content) also show a linear increment pattern with an increase in their levels. But incubation temperature shows otherwise; although the highest level of incubation temperature tested resulted in highest immobilized lipase activity, its mid-point shows a downward curvature in its response.

The normality of data obtained can be obtained through plotting the normal probability plot of residuals. The residual values explain the difference between the observed and predicted value of the regression. From Figure 2 (a), the experimental points

Main effects plot for lipase activity (U) - Data means

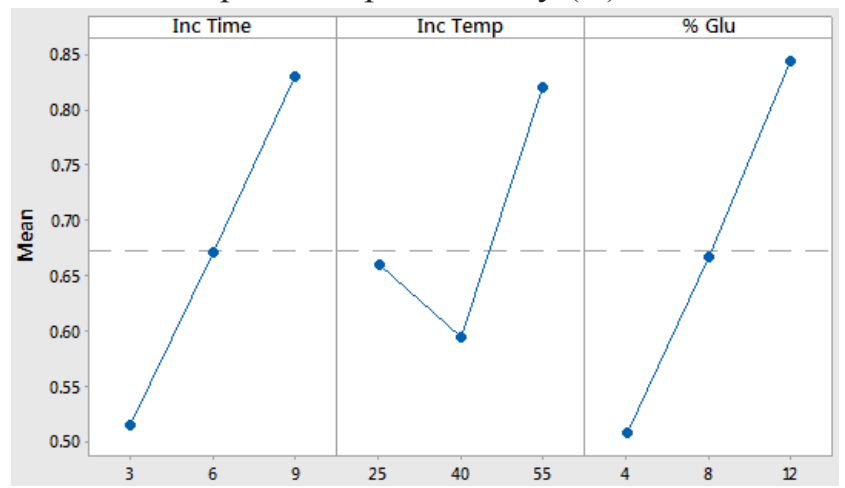

Figure 1. Main effect plot for each parameter tested on lipase immobilization efficiency on maghemite.

Residual plots for lipase activity (U)
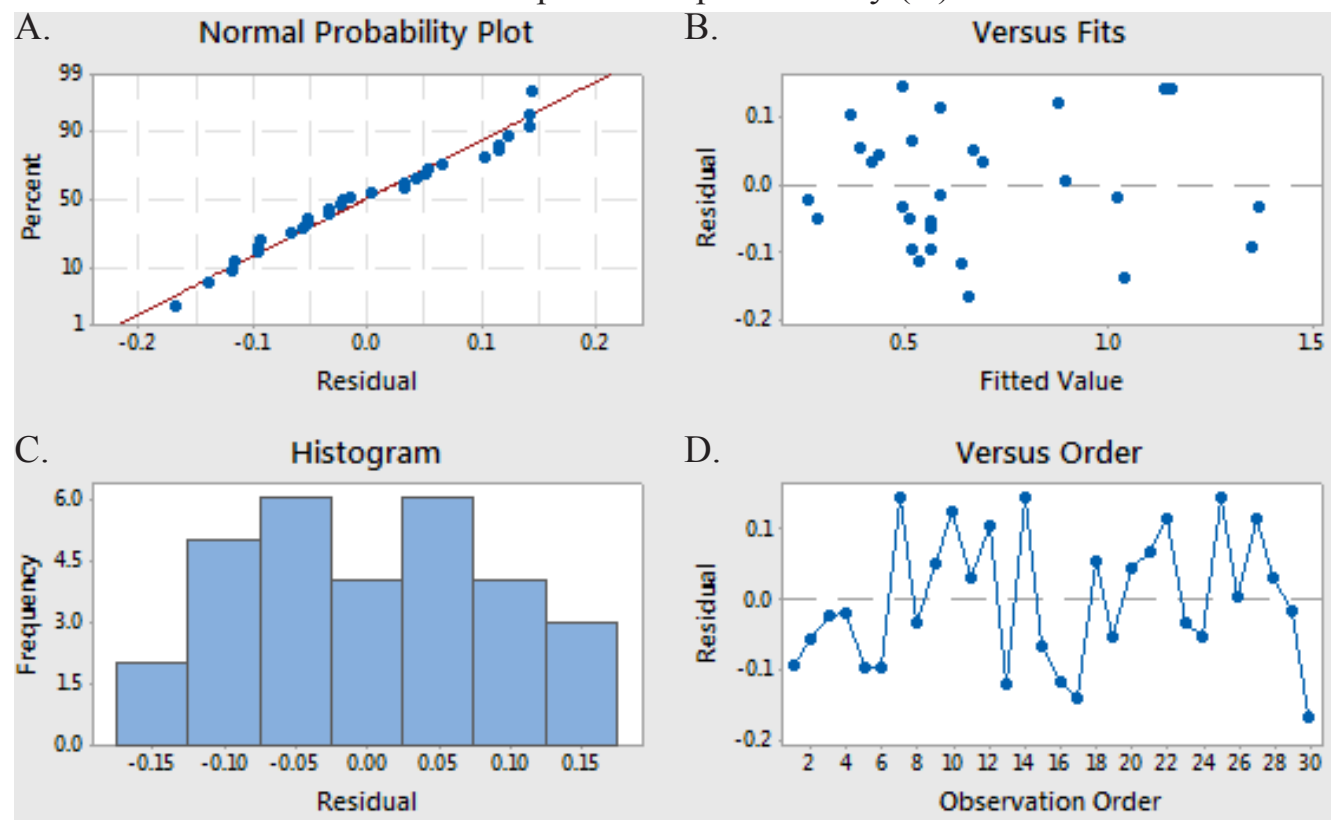

Figure 2. (a) Normal Probability plot for residual value, (b) Residual plots against fitted value, (c) Histogram of residual value, (d) Residual plot against observation order. 
aligned on the suggesting normal probability plot show that the data is not skewed anywhere and compliance with normality of data. Figure 2 (b) shows plots of residuals versus fitted values. From the data, the residuals are randomly scattered around the zero line, suggesting there is no bias in the variance. Figure 2 (c) show a histogram plot with symmetrical observation, further supporting the normality of the data. Figure 2 (d) shows that the residuals are randomly scattered with observation order further confirming the non-bias of the data.

3D surface plots were plotted to see the potential interaction effect between all parameters used. The plots are able to describe a continuous response when two different parameters are applied. Figure 3 (a) shows interaction between incubation time and incubation temperature towards immobilized lipase activity. From the plot, it was found the highest enzyme activity occurs when both incubation temperature and incubation time are at their highest point. A downward curvature in response was observed when the levels progress from the lower points to their upper points. Figure 3 (b) shows similarity in response to 3(a), but a more downward curvature was observed as the combination points for glutaraldehyde content and incubation temperature progress from their lower to the upper point. A sharp increase was observed in Figure 3 (c) in the 3D surface plot between incubation time and glutaraldehyde content There was merely a curvature observed along the point distribution.

In order to find the optimized region, the response optimizer (Figure 4) was used in determining to combination of operating parameters that will result in the desired condition. Both weight and importance were set at 1 . The response optimizer was set to the maximum immobilized lipase activity value of $1.8 \mathrm{U}$. The global solution was found to be at combination points of 9 hours of incubation time, $55^{\circ} \mathrm{C}$ incubation temperature and $12 \%(\mathrm{v} / \mathrm{v})$ glutaraldehyde with a desirability score of 1 .

\section{Characteristics of synthesized and lipase immobilized maghemite nanoparticles}

Infrared Spectra of Synthesized Maghemite, Surface Functionalized Maghemite and Lipase enzyme

Characterization of synthesized, surface functionalized maghemite and free lipase was performed using FT-IR spectra, as shown in Figure 5. All peaks attributed to free lipase enzyme based on Figure 5 (a) appeared in Figure 5 (c) indicating the succesful lipase immobilization on maghemite complex nanoparticles. Figure 5 (b) shows the pure chitosan before the cross-linking reaction. The broad peak around $3420 \mathrm{~cm}^{-1}$ indicates the stretching vibration of $\mathrm{v}-\mathrm{NH}_{2}$ of chitosan that is overlapped with $\mathrm{OH}^{-}$stretch and the peak around $1640 \mathrm{~cm}^{-1}$ represents the amide
Surface plot of lipase activity (U) vs Inc Time, Inc Time

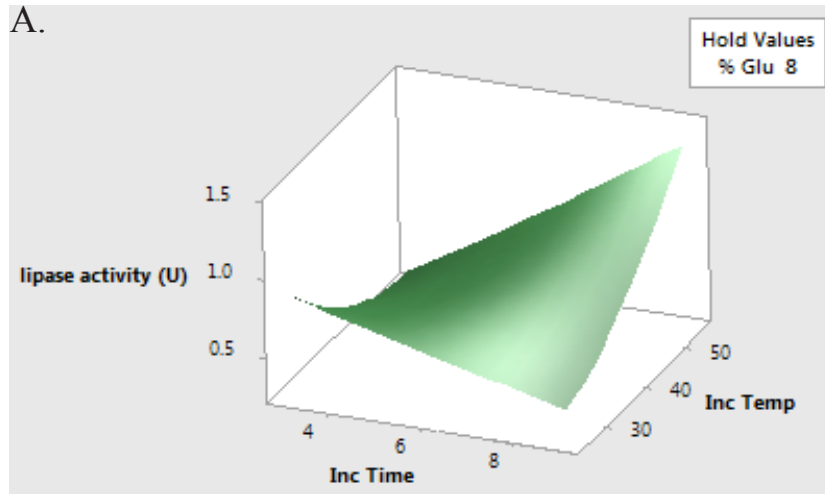

Surface plot of lipase activity (U) vs \% Glu, Inc Time B.

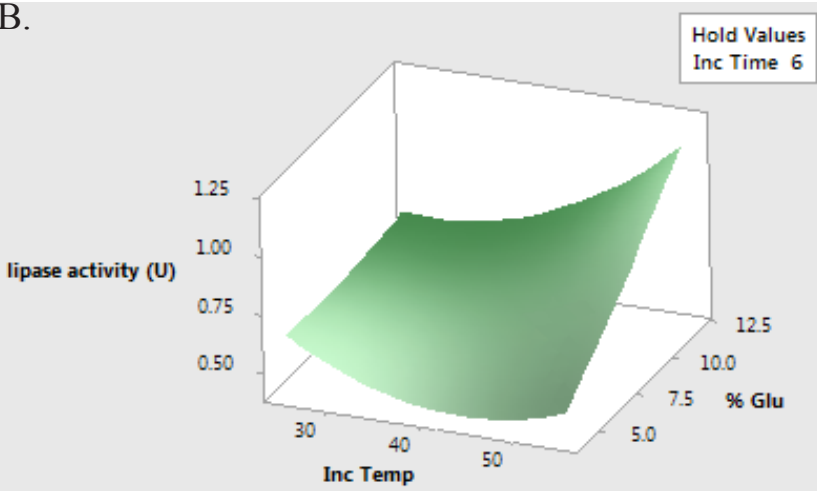

Surface plot of lipase activity (U) vs \% Glu, Inc Time C.

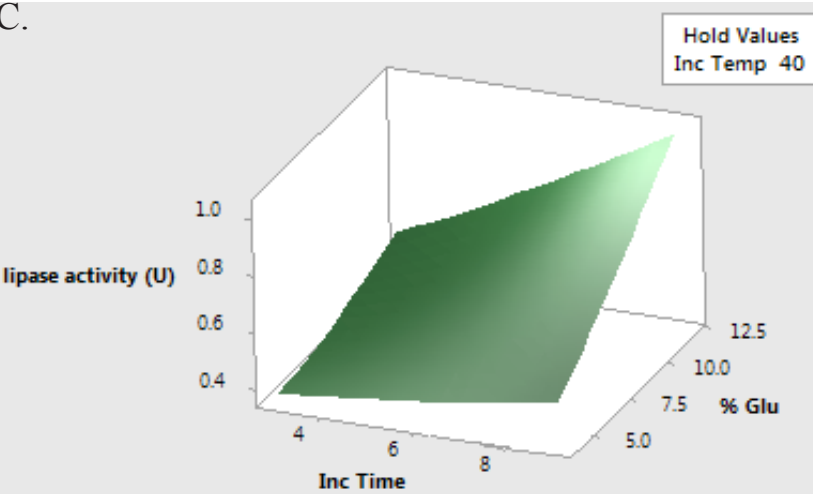

Figure 3. (a) $3 \mathrm{D}$ surface plot between incubation time and incubation temperature, (b) 3D surface plot between incubation temperature and glutaraldehyde content, (c) 3D surface plot between incubation time and glutaraldehyde content.

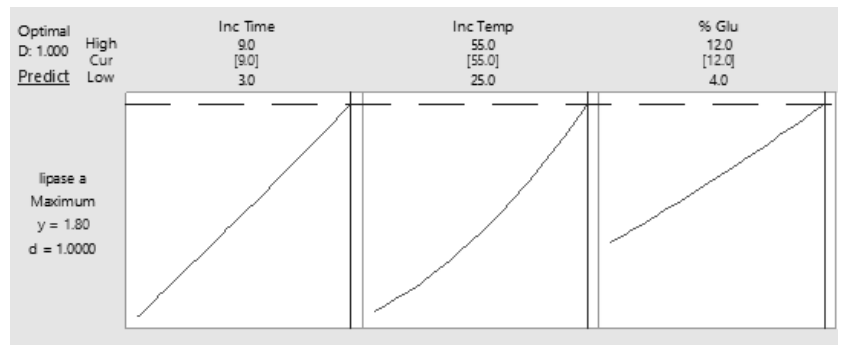

Figure 4. Response optimizer plot. 


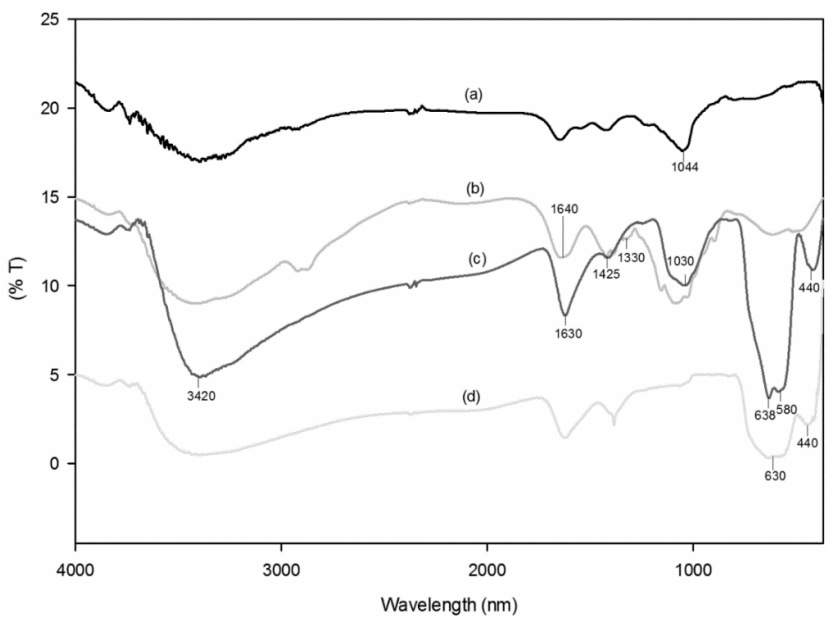

Figure 5. FT-IR spectra for (a) Free lipase; (b) Chitosan; (c) Immobilized lipase on maghemite complex; (d) Bare maghemite.

group (Ou \& Bo, 2017). The shifted peak around 1630 $\mathrm{cm}^{-1}$ in Figure 5 (c) is attributed to the linked chitosan. New peaks at $640 \mathrm{~cm}^{-1}$ and $580 \mathrm{~cm}^{-1}$ correspond to the layer of chitosan coated on maghemite (Hojnik, Knez, \& Leitgeb, 2013). The broad peak at $630 \mathrm{~cm}^{-1}$ and peak at $440 \mathrm{~cm}^{-1}$ in Figure 5 (d) indicate the Fe-O bond in maghemite. The structure of the synthesized maghemite/lipase composite is shown in Figure 6.

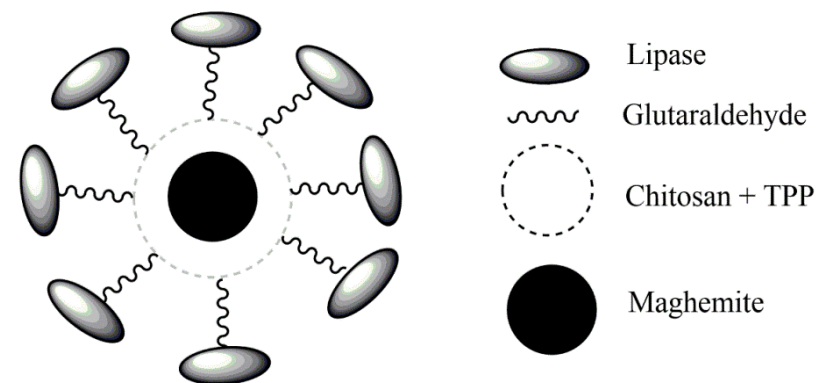

Figure 6. Maghemite / lipase composite structure.

\section{X-Ray Diffraction Microscopy}

Verification of maghemite was conducted using X-Ray diffraction (XRD) by applying $\mathrm{CuK} \alpha(\lambda=$ $0.154 \mathrm{~nm}$ ) radiation from 20 - 70 degrees. The obtained diffraction peaks were analyzed and found to be consistent with standard maghemite (JCDPS card No. 39-1346). The XRD peaks of the nano-crystallite match well with the standard of $\gamma-\mathrm{Fe}_{2} \mathrm{O}_{3}$ where the peaks are at $2 \theta=30.3^{\circ}, 35.6^{\circ}, 43.4^{\circ}, 53.7^{\circ}, 57.0^{\circ}$ and $63.0^{\circ}$ which correspond to the (220), (311), (400), (422), (511) and (440) reflections of $\gamma-\mathrm{Fe}_{2} \mathrm{O}_{3}$, respectively (Ngadiman et al., 2015). The diffraction pattern obtained during the analysis is shown in Figure 7.

\section{Electron microscopy}

High Resolution Transmission Electron Microscopy (HRTEM) was used to study the size, morphology, degree of crystallinity, as well as dispersion, of

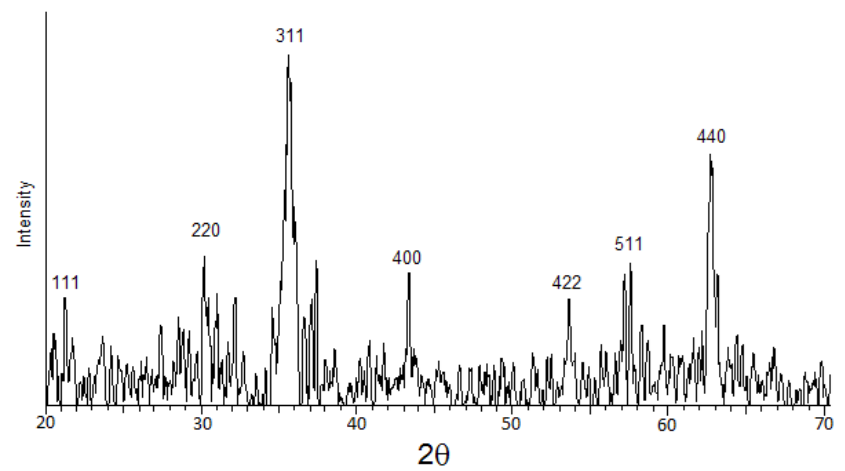

Figure 7. X-Ray diffractogram for synthesized maghemite.

synthesized maghemite. Figure 8 shows the image of synthesized maghemite. The spherical shape of maghemite was observed with a size distribution in the range of 2.01-3.0 nm, as shown in Figure 8(a) and (b)

\section{A}

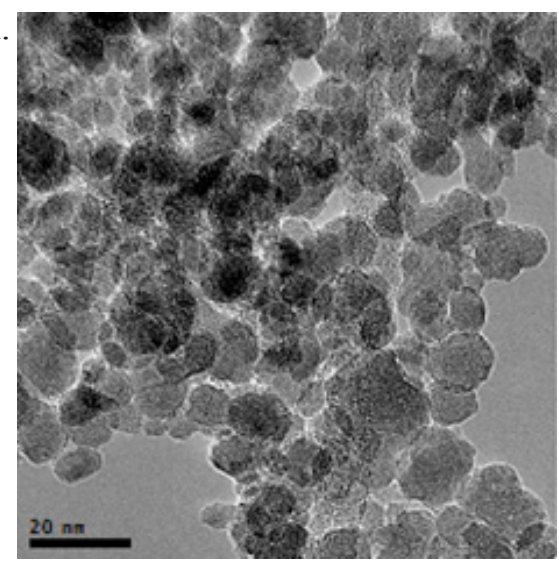

B.
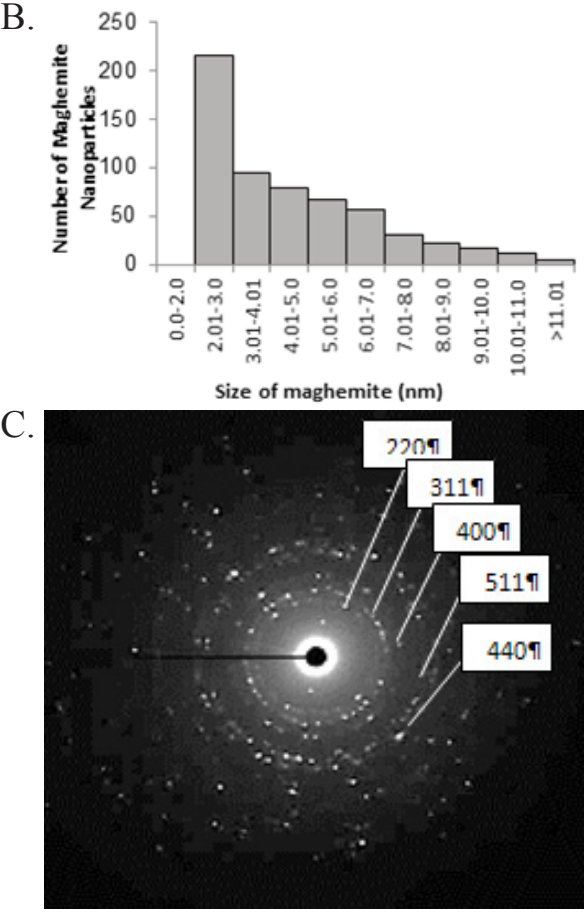

Figure 8. (a) HR-TEM Image of maghemite, (b) size distribution of maghemite nanoparticle, (c) SAED figure of maghemite nanoparticle. 
respectively. The polycrystallinity of maghemite was evident with formation of rings in the Selected Area Electron Diffraction (SAED) pattern (Figure 8(c)). Interplanar spacings (d-values) of maghemite were also calculated and compared with standard values from JCDPS card \#39-1346 to confirm further the type of iron oxide nanoparticles synthesized (Cheng, Tang, Qi, Sheng, \& Liu, 2010). Obtained d-values were in good agreement with the standard values, further indicating that the type of iron oxide nanoparticles synthesized were maghemite. The comparison of values is tabulated in Table 5.

Table 5. Comparison of $d$-spacing values between SAED and standard JCDPS \#39-1346.

\begin{tabular}{ccc}
\hline $\begin{array}{c}\mathbf{h}, \mathbf{k}, \mathbf{l} \\
\text { value }\end{array}$ & $\begin{array}{c}\text { sample } \\
\text { d value }(\AA)\end{array}$ & $\begin{array}{c}\text { JCDPS \#39-1346 } \\
\text { d value }(\AA)\end{array}$ \\
\hline 220 & 2.90 & 2.95 \\
311 & 2.50 & 2.52 \\
400 & 2.10 & 2.09 \\
511 & 1.63 & 1.61 \\
440 & 1.50 & 1.48 \\
\hline
\end{tabular}

\section{Thermal properties of Synthesized Maghemite}

Figure 9 shows the DSC thermogram of maghemite in the temperature range of $25^{\circ} \mathrm{C}$ until $500^{\circ} \mathrm{C}$. An exothermic peak was observed at $456.3^{\circ} \mathrm{C}$ indicating the transition of maghemite to hematite. This is similar to the result reported by (Rocher, Manerova, Kinnear, Evans, \& Francesconi, 2014), who recorded the transition temperature of maghemite to hematite below $500^{\circ} \mathrm{C}$. Perhaps, this is due to the smaller size of the maghemite synthesized (Darezereshki, 2011). The occurrence of phase change from maghemite to hematite at the stated temperature is due to a structural change from cubic to hexagonal phase where the system will have a lower state of free energy (Pati \& Philip, 2011). The exothermic phase change enthalpy provides the amount of energy released and is based on integration of the peak in the curve and subsequent division by the mass of sample used. Based on the

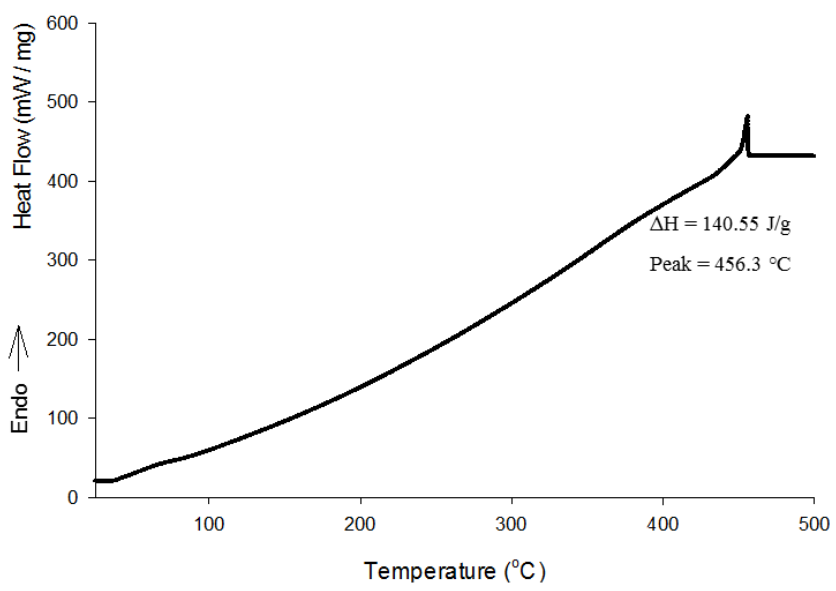

Figure 9. DSC Thermogram for Maghemite. thermogram as depicted in Figure 8, the enthalpy of phase change was $140.55 \mathrm{~J} \mathrm{~g}^{-1}$ of maghemite. The entropy in the system was also calculated using the transition temperature $(\mathrm{K})$ and enthalpy $\left(\mathrm{J} \mathrm{g}^{-1}\right)$ values and the value obtained was $0.19 \mathrm{~J} \mathrm{~g}^{-1} \mathrm{~K}^{-1}$.

The thermal properties of the synthesized maghemite were investigated using thermogravimetric analysis (TGA) in order to study its thermal stability. By doing TGA analysis, the amount of weight loss can be monitored with increase in temperature. Based on the thermogram in Figure 10, it is observed that the decomposition pattern of maghemite appeared in two stages. The first stage of weight loss appeared from ambient temperature until $100^{\circ} \mathrm{C}$. This initial weight loss is associated with evaporation of water from the sample. A second weight loss observed in the range between $350^{\circ} \mathrm{C}$ to $420^{\circ} \mathrm{C}$ might be due to pyrolysis of organic compounds present in the composite (Chaudhari et al., 2011). Conversion of maghemite to hematite afterwards occurred without any weight loss.

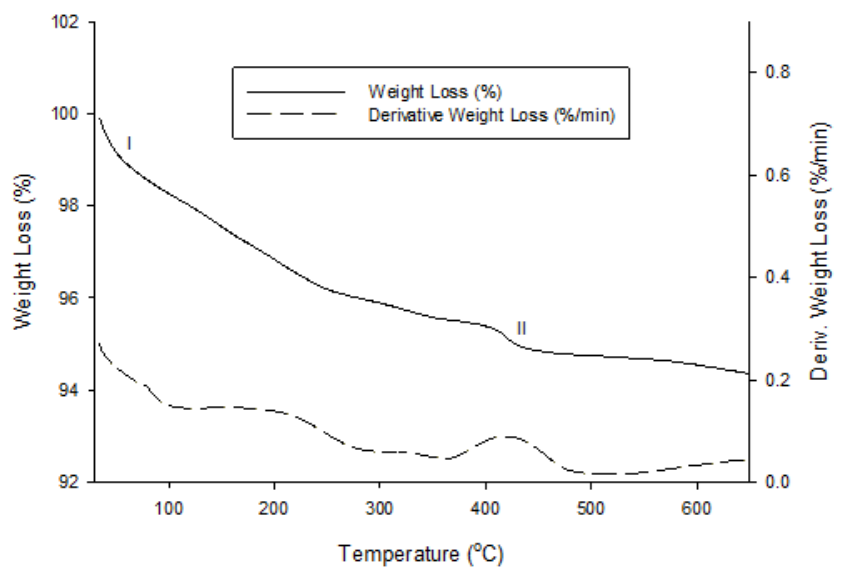

Figure 10. TGA curve for Maghemite.

\section{Magnetization of Untreated Maghemite and Lipase Immobilized Maghemite}

The magnetic properties of lipase immobilized maghemite were compared with the untreated maghemite through characterization using a vibrating sample magnetometer (VSM) at room temperature (Figure 11). Parameters such as saturation magnetization (Ms), coercivity field ( $\mathrm{Hc}$ ), and remanent magnetization (Mr) were evaluated. For both products, the presence of superparamagnetic properties was evident due to the almost null coercivity and retentivity values for both samples. The saturation magnetization of lipase/maghemite composite increased more than twice that of the untreated maghemite. This is due to the increase in size of the maghemite nanoparticles post surface modification and lipase immobilization which led to the increase in the saturation magnetization (Immanuel et al., 2015). The parameter values for both samples are shown in Table 6. 
Table 6. Magnetic properties for Both Maghemite and Lipase/Maghemite Composite.

\begin{tabular}{cccc}
\hline Sample & $\begin{array}{c}\text { Saturation } \\
\text { Magnetization } \\
\text { (emu) }\end{array}$ & $\begin{array}{c}\text { Coercivity } \\
\text { (G) }\end{array}$ & $\begin{array}{c}\text { Remanent } \\
\text { Magnetization } \\
\text { (memu) }\end{array}$ \\
\hline $\begin{array}{c}\text { Untreated } \\
\text { Maghemite } \\
\text { Lipase / } \\
\begin{array}{c}\text { Maghemite } \\
\text { composite }\end{array}\end{array}$ & 34.3 & 0.5 & 0.62 \\
\hline
\end{tabular}

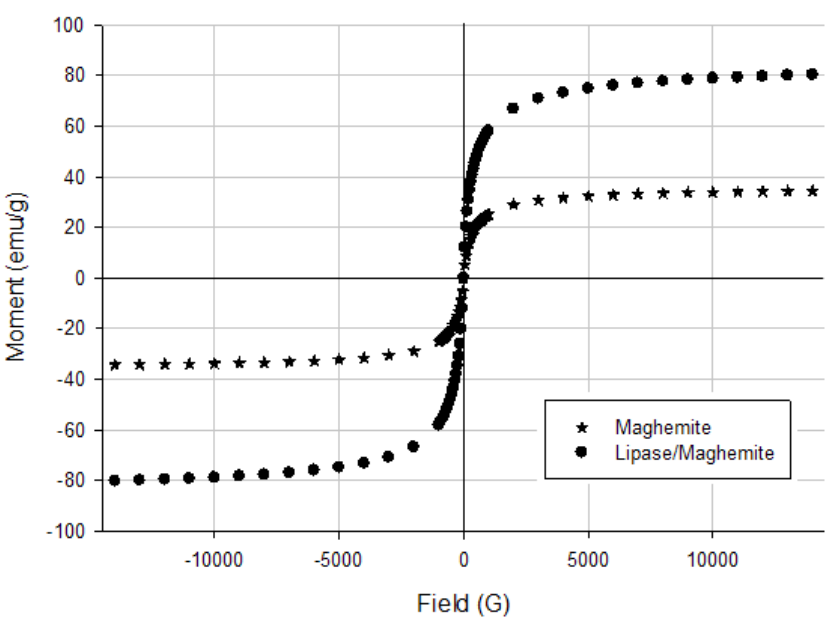

Figure 11. Hysteresis Loop for Both Maghemite and Lipase/Maghemite Composite.

\section{CONCLUSION}

Immobilization of lipase enzyme on maghemite was successful with good enzyme activity recorded. The surface of maghemite was modified by adding -NH functional groupa and applying glutaraldehyde as cross-linker to the magnetic nanomaterial to further enhance lipase attachment. Characterization of physicochemical properties was performed to investigate the quality of synthesized products. FT-IR spectra were used to confirm the successful immobilization of lipase onto maghemite. We found that the synthesized maghemite was of high purity with a size distribution mainly between 2-3 nm, thus able to provide very large surface area for enzyme attachment. Transition of synthesized maghemite to hematite occurred at $456.3^{\circ} \mathrm{C}$ with enthalpy and entropy values of 140.55 $\mathrm{J} / \mathrm{g}$ and $0.19 \mathrm{~J} \mathrm{~g}^{-1} \mathrm{~K}^{-1}$ respectively. It was also found that the saturation magnetization of immobilized lipase/ maghemite composite was higher than the untreated but did not affect its superparamagnetic properties.

\section{ACKNOWLEDGMENT}

The authors acknowledge the financial assistance by the Ministry of Higher Education (MOHE) Malaysia for the HICOE (Vote no: 4C152) and FRGS (Vote No: 4F446) funding sources.

\section{REFERENCES}

Chaudhari, N. S., Warule, S. S., Muduli, S., Kale, B. B., Jouen, S., Lefez, B., Hanoyer., and Ogale, S. B. Maghemite (hematite) core (shell) nanorods via thermolysis of a molecular solid of Fe-complex. Dalton Transaction. 40, 8003-8011 (2011). https:// doi.org/10.1039/c1dt10319a

Cheng, W., Tang, K., Qi, Y., Sheng, J., and Liu, Z. Onestep synthesis of superparamagnetic monodisperse porous $\mathrm{Fe}_{3} \mathrm{O}_{4}$ hollow and core-shell spheres. Journal of Materials Chemistry, 20, 1799-1805 (2010). https://doi.org/10.1039/b919164j

Chiou, S.-H., and Wu, W.-T. Immobilization of Candida rugosa lipase on chitosan with activation of the hydroxyl groups. Biomaterials, 25, 197-204 (2004). https://doi.org/10.1016/S0142-9612(03)00482-4

Cipolatti, E. P., Silva, M. J. A., Klein, M., Feddern, V., Feltes, M. M. C., Oliveira, J. V., Ninow, J.L and de Oliveira, D., Current status and trends in enzymatic nanoimmobilization. Journal of Molecular Catalysis B: Enzymatic, 99, 56-67 (2014). https:// doi.org/10.1016/j.molcatb.2013.10.019

Darezereshki, E. One-step synthesis of hematite $\left(\alpha-\mathrm{Fe}_{2} \mathrm{O}_{3}\right)$ nano-particles by direct thermaldecomposition of maghemite. Materials Letters, 65, 642-645 (2011). https://doi.org/10.1016/j. matlet.2010.11.030

Ghadi, A., Tabandeh, F., Mahjoub, S., Mohsenifar, A., Roshan, T., and Alavije, S. Fabrication and Characterization of Core-Shell Magnetic Chitosan Nanoparticles as a Novel carrier for Immobilization of Burkholderia cepacia Lipase. Journal of Oleo Science, 64, 423-430 (2015). https://doi. org $/ 10.5650 /$ jos.ess 14236

Hojnik, G., Knez, Ž., and Leitgeb, M. Different preparation methods and characterization of magnetic maghemite coated with chitosan. Journal of Nanoparticle Research, 15, 1751 (2015). https:// doi.org/10.1007/s11051-013-1751-x

Idris, A., Ismail, N. S. M., Hassan, N., Misran, E., and Ngomsik, A.-F. Synthesis of magnetic alginate beads based on maghemite nanoparticles for $\mathrm{Pb}$ (II) removal in aqueous solution. Journal of Industrial and Engineering Chemistry, 18, 1582-1589 (2012). https://doi.org/10.1016/j.jiec.2012.02.018

Immanuel, M., Denison, J., Raman, S., Duraisamy, N., Thangavelu, R. M., Riyaz, S. U. M., Gunasegaran, D and Krishnan, K. Preparation, characterization and application of antibody-conjugated magnetic nanoparticles in the purification of begomovirus. RSC Advances, 5, 99820-99831 (2015). https://doi. org/10.1039/C5RA17982C

Jaiswal, N., Prakash, O., Talat, M., Hasan, S. H., and Pandey, R. K. $\alpha$-Amylase immobilization on gelatin: Optimization of process variables. 
Journal of Genetic Engineering and Biotechnology, 10, 161-167 (2012). https://doi.org/10.1016/j. jgeb.2012.03.003

Kim, B. C., Nair, S., Kim, J., Kwak, J. H., Grate, J. W., Kim, S. H., and Gu, M. B. Preparation of biocatalytic nanofibres with high activity and stability via enzyme aggregate coating on polymer nanofibres. Nanotechnology, 16, S382-S388 (2005). https:// doi.org/10.1088/0957-4484/16/7/011

Kuo, C. H., Liu, Y. C., Chang, C. M. J., Chen, J. H., Chang, C., and Shieh, C. J. Optimum conditions for lipase immobilization on chitosan-coated Fe3O4 nanoparticles. Carbohydrate Polymers, 87, 2538-2545 (2012). https://doi.org/10.1016/j. carbpol.2011.11.026

Liu, X., Chen, X., Li, Y., Wang, X., Peng, X., and Zhu, W. Preparation of superparamagnetic $\mathrm{Fe}_{3} \mathrm{O}_{4} @$ alginate/chitosan nanospheres for Candida rugosa lipase immobilization and utilization of layerby-layer assembly to enhance the stability of immobilized lipase. ACS Applied Materials \& Interfaces, 4, 5169-5178 (2012). https://doi. org/10.1021/am301104c

Ngadiman, N. H. A., Idris, A., Irfan, M., Kurniawan, D., Yusof, N. M., and Nasiri, R. $\gamma-\mathrm{Fe}_{2} \mathrm{O}_{3}$ nanoparticles filled polyvinyl alcohol as potential biomaterial for tissue engineering scaffold'. Journal of the Mechanical Behavior of Biomedical Materials, 49, 90-104 (2015). https://doi.org/10.1016/j. jmbbm.2015.04.029

$\mathrm{Ou}, \mathrm{A}$. , and Bo, I. Chitosan Hydrogels and their Glutaraldehyde-Crosslinked Counterparts as Potential Drug Release and Tissue Engineering Systems -
Synthesis, Characterization, Swelling Kinetics and Mechanism. J Phys Chem Biophys, 7, 1-7 (2017). https://doi.org/10.4172/2161-0398.1000256

Pati, S. S., and Philip, J. Enhancement in maghemite to hematite phase transition temperature with very low fraction of $\mathrm{Co}$ (II) doping. In International Conference on Nanoscience, Engineering and Technology (ICONSET 2011), 323-325. https:// doi.org/10.1109/ICONSET.2011.6167973

Rocher, V., Manerova, J., Kinnear, M., Evans, D. J., and Francesconi, M. G. Direct amine-functionalisation of $\gamma-\mathrm{Fe}_{2} \mathrm{O}_{3}$ nanoparticles. Dalton Transactions, 43, 2948-2952 (2014). https://doi.org/10.1039/ C3DT52386A

Romdhane, I. B.-B., Romdhane, Z. Ben, Gargouri, A., and Belghith, H. Esterification activity and stability of Talaromyces thermophilus lipase immobilized onto chitosan. Journal of Molecular Catalysis B: Enzymatic, 68, 230-239 (2011). https://doi. org/10.1016/j.molcatb.2010.11.010

Saravanan, A., and Ramasamy, R. P. Investigation of polymer dynamics in chitosan-maghemite nanocomposites: a potential green superparamagnetic material. Journal of Polymer Research, 23, 104 (2016). https://doi.org/10.1007/ s10965-016-0998-1

Shaarani, S. M., Jahim, J. M., Rahman, R. A., Idris, A., Murad, A. M. A., and Illias, R. M. Silanized maghemite for cross-linked enzyme aggregates of recombinant xylanase from Trichoderma reesei. Journal of Molecular Catalysis B: Enzymatic, 133, 65-76 (2016). https://doi.org/10.1016/j. molcatb.2016.07.006 
